\title{
A reverse Kamin effect in the escape and avoidance conditioning of newly hatched chicks
}

PHILIP H. GRAY, ALLEN T. YATES, DEL R. VANDIVER, AND KAREN KIRWAN, MONTANA STATE UNIVERSITY

This study ascertained why an earlier experiment found newly hatched chicks to be poor learners in a shock avoidance situation. A technological problem of passing an electric current through the naturally insulated feet of the chick was identified. This rectified, one-day-old chicks will demonstrate escape conditioning when the response terminates both $C S$ and UCS. They will demonstrate both escape and avoidance conditioning when the response terminates only the UCS.

Newly hatched chicks can imprint to objects in their environment, although perhaps not as well as some early experiments testified (Gray, 1966). But James \& Binks (1963) failed to find either escape or avoidance conditioning in one-day-old chicks, or avoidance conditioning in two-day-olds. Our study was intended as a clarification of the James-Binks results, which, if corroborated, would suggest that imprinting is a simpler form of learning and that the more complicated phenomenon of conditioning requires a period of maturation in the chick.

Method

The instrumental conditioning box was 16 in. $x 24$ in. by 12 in. high. The floor was a grid of parallel steel bars across the shorter dimension; these bars were $1 / 4 \mathrm{in}$. in diameter and $5 / 8$ in. from center to center. On one long side of the box, a clear plastic window began 2 in. above the grid and continued to within 2 in. of sides and top. Facing the window from the outside, the left side of the box was painted white and the right side black. The lid and a wooden floor positioned $1 / 2$ in. below the steel bars were painted correspondingly. In the exact center of the lid was a 25-W light bulb and to the rear of this a buzzer. Between $E$ and the window was a slotted screen through which $\mathrm{S}$ was observed.

In Experiment 1, eight White Leghorn chicks, ranging in age from 12 to $15 \mathrm{~h}$, were trained as follows. Electrode paste was smeared on S's feet and it was placed, facing the window, in the center of the compartment where shock would be delivered. A button was then pressed which switched on the dual signals (CS) of buzzer and light and the automatic timers. After $10 \mathrm{sec}$ an electric current was swept across adjacent bars of the floor, and both shock (UCS) and CS continued for 30 sec more, or until S crossed to the other compartment, whichever occurred first. After termination of the trial, $S$ was taken from the apparatus and placed in a holding box for the $20 \mathrm{sec}$ intertrial interval. One hundred trials were run for each $S$ in as many minutes. This was the
James-Binks procedure. The removal of $\mathrm{S}$ from the box when it completed a crossing in less than $40 \mathrm{sec}$ was predicated on Kamin's finding that learning in rats is better when a response terminates the CS that was associated with pain (cf., Kimble, 1961, p. $154 \mathrm{ff}$ ). Half the $\mathrm{Ss}$ were run with the black compartment hot and half with the white hot; we used electrode paste for each trial; and the temperature in the room where hatching, holding, and testing occurred was $100^{\circ} \mathrm{F}$, with relative humidity about $50 \%$.

In Experiment 2, the James-Binks practice of removing the $S$ from the apparatus as soon as it had crossed was omitted. The eight Ss of this experiment were left in the box the full 40 sec of a trial, regardless of response.

Experiment 3 was the same as Experiment 2, except that the eight $\mathrm{Ss}$ ranged in age from 34 to $36 \mathrm{~h}$ post-hatch.

Experiment 4 was an attempt to duplicate the results of James and Binks. For this purpose, the plastic observation window was closed on the safe side, temperature was lowered to $90^{\circ} \mathrm{F}$, the CS was now a $60-W$ bulb placed 4 in. from the window (which raised the interior temperature immediately inside the box by several degrees), only the white half of the box was hot, and the Ss were removed from the box as soon as they crossed the line. Several chicks were run before we initiated two further steps on a last group of eight. First, we used very young Ss, 2 and $3 \mathrm{~h}$ old, which had not gained muscular tonus. Second, like James and Binks, we applied electrode paste only once every 10 trials.

Experiment 5 was a series of follow-up trials using six good learners from Experiments 2 and 3. They were placed on the safe rather than shock side at the beginning of a trial.

\section{Results and Discussion}

The results of Experiment 1 are depicted in Fig. $1 \mathrm{~A}$ (Day 1 Interrupted). None of the eight Ss learned to avoid the shock, that is, none learned to go to the other compartment during the $10 \mathrm{sec}$ safety interval when light and buzzer were on but before the grid was electrified. Mean latencies to escape, however, showed a consistent decrease over the 100 trials, contrary to the latencies for the James-Binks day-old chicks which increased, as shown in Fig. $1 \mathrm{~B}$.

As can be seen in Fig. 1A (Day 1 Uninterrupted), the effect of permitting the chick an opportunity to associate the cessation of shock with the cues pres- 


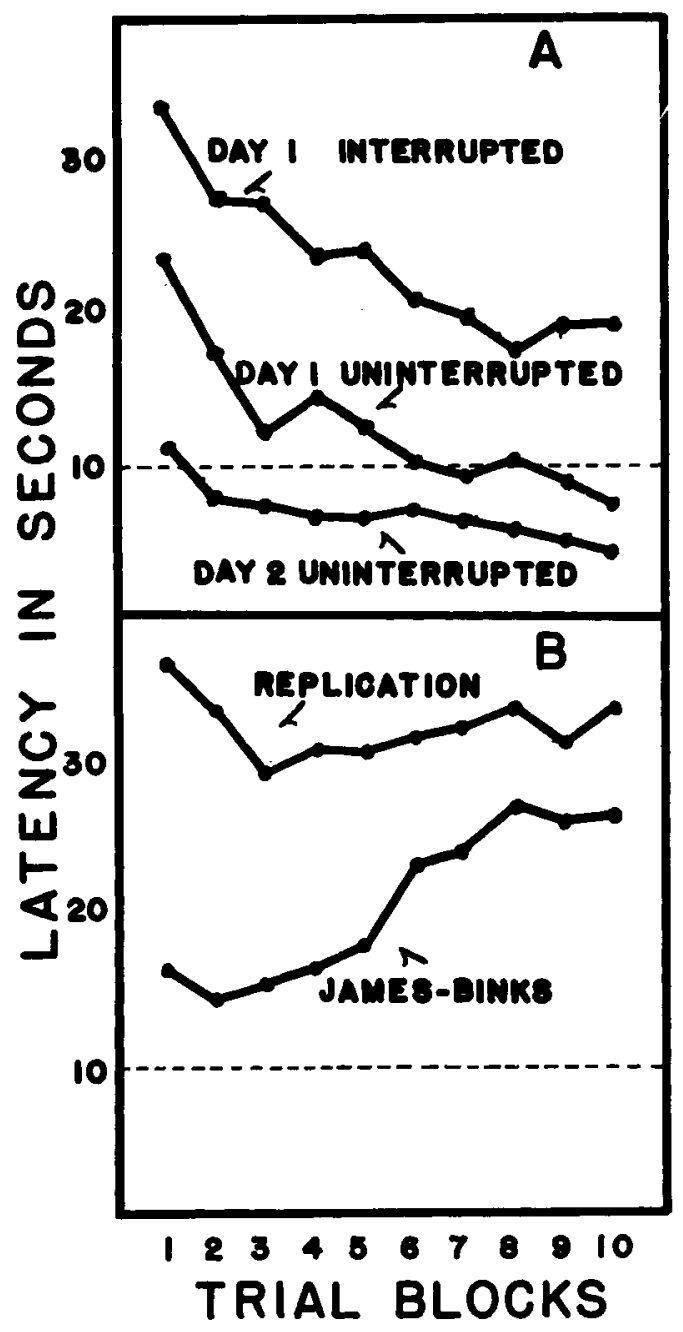

Fig. 1. Mean latencies for each block of $\mathbf{1 0}$ trials.

ent in the box was dramatic. The final mean latencies in Experiment 2 were less than $10 \mathrm{sec}$, well below the avoidance learning cut-off. By this simple expedient of leaving the Ss in the box throughout the trial period we visibly improved learning.

Experiment 3 showed that the increased vigor of two-day-old chicks yields better performances. In Fig. IA (Day 2 Uninterrupted), the mean avoidance latency by the end of 20 trials is less than $10 \mathrm{sec}$.

A mixed-model analysis of variance for latencies in these three experiments produced significances less than 0.01 for Experiments, Trial Blocks, and Interaction. The caliber of learning seemed so high that the next problem was to find out why James and Binks had, in effect, failed. Using their general procedure in Experiment 4, we found conditioning to be degraded, but we had no success in obtaining an increasing latency for day-olds until we used younger chicks and applied electrode paste only once every 10 trials. A peculiarity of paste is that after drying (which occurs in a few minutes) it becomes an insulation, creating more skin resistance than existed before application. The resistance of a normally dry chicken foot is high to begin with, in the megohm range. After one thorough application of paste, the resistance falls to about a kilohm. Successive applications at $1-\mathrm{min}$ intervals brings the resistance down to a point where chicks in our apparatus would be receiving close to $1 \mathrm{~mA}$ of current. To illustrate the difference in natural insulation, we discovered that a rat with paste on its feet would cry audibly at a voltage setting that a chick with similarly treated feet would ignore.

Under these conditions, i.e., terminating a trial as soon as $\mathrm{S}$ crossed the safety line, high skin resistance, and very young Ss, we obtained a curve which, like that of James and Binks, showed first a decrease in latency and then an increasing latency (Fig. 1B). To be sure, we overshot the mark and got more exaggerated results, but perhaps if we had altered one factor, such as using chicks that were a few hours older, we could have brought the curves closer together.

In Experiment 5, we satisfied our curiosity about what it was that the chicks were learning. All but one of the six tested remained on the safe side during the new trials, some of them even retreating from the center of the safe compartment to the far corners. The chick that ran to the shock side inhibited its running after two trials. One chick that stayed on the safe side had been shocked during only the first three of its 100 training trials, and never received a shock afterward. Apparently the chicks learned color discrimination as well as an instrumental response.

Although Kamin's studies with rats indicated they learned better when their response removed them from the punishing situation, this was not true for young chicks, which on a previous occasion in the senior author's experience had solved a discrimination problem more efficiently than rats (Gray, 1957).

\section{References}

GRAY, P. H. Irrelevant cue learning in the chick. Psychol Rep., 1957, 3, 345-352.

GRAY, P. H. The comparative analysis of behavior. Dubuque: Wm. Brown, 1966.

JAMES, H., \& BINKS, CAROLYN. Escape and avoidance learning in newly hatched domestic chicks. Science, 1963, 139, 1293-1294. KIMBLE, G. A. Hilgard and Marquis' conditioning and leaming. New York: Appleton-Century-Crofts, 1961. Note

1. The research reported here was supported by U. S. Public Health Service Grants MH-05766 and HD-00877. The conditioning apparatus was built at MSU by Hugh Via and Richard Nutter. It is purely coincidental in this regard that Mr. Nutter later married Miss Binks. We initially reported these experiments at the Rocky Mountain Psychological Meeting in 1964. The results were sent to $\mathrm{H}$. James and our own publication delayed pending a decision by recipient to act on our offer to amalgamate our results with any experiment he might do to reconcile our different findings. 